\title{
Análise retórica de introduções de artigos científicos da área da saúde pública
}

\author{
Fernanda Goulart Ritti Dias \\ Universidade Federal de Alagoas \\ fergoulart@hotmail.com \\ Benedito Gomes Bezerra \\ Universidade de Pernambuco \\ beneditobezerra@gmail.com
}

\begin{abstract}
Resumo
A crescente demanda pela publicação de artigos científicos tem levado pesquisadores a preocuparem-se cada vez mais com a escrita no ambiente acadêmico. Sendo a introdução uma das seções responsáveis pela garantia de publicação do artigo e ainda pela aceitação do trabalho pela comunidade cientifica, merece, assim, especial atenção no momento de sua redação. Dessa forma, esta pesquisa teve como objetivo verificar, por meio da aplicação do Modelo CARS (SWALES, 1990), de que modo introduções de artigos científicos da área da saúde pública são organizadas retoricamente. Foram analisadas as introduções de dez artigos científicos redigidos em língua portuguesa e publicados em revistas indexadas na base de dados Scielo no ano de 2012. Os resultados indicam que a maioria dos artigos adota uma organização retórica das informações coerente com as opções previstas no modelo de análise utilizado.
\end{abstract}

Palavras-chave: Artigo científico. Introduções acadêmicas. Organização retórica. Saúde pública.

\begin{abstract}
The increasing demand for publishing research articles has led researchers to a growing concern about writing in academic settings. Since introduction is one of the sections responsible for guaranteeing the publication of an article and its consequent acceptance by the scientific community, it deserves special attention at the moment of writing. Hence, the objective of the present paper is to verify how introductions in public health research articles are rhetorically organized, based on the CARS Model designed by Swales (1990). Therefore,
\end{abstract}

Horizontes de Linguística Aplicada, ano 12, n. 1, 2013163 
we analyze 10 introductions of research articles written in Portuguese, and published in journals indexed at Scielo database in the year 2012. Results indicate that most articles adopt a rhetorical organization of information that is coherent with the options provided in the model.

Keywords: Research article. Academic introductions. Rhetorical analysis. Public health.

\section{Introdução}

A atual necessidade de publicação de artigos científicos entre pesquisadores de diversas áreas tem elevado significativamente os números da produção científica nacional (VOLPATO; FREITAS, 2003). Henz (2003) ressalta que esse crescimento se deve, principalmente, à importância que esse gênero textual assumiu na academia, sendo considerado um dos principais meios para a disseminação da ciência e para se alcançar prestígio entre os pares. Além disso, nos últimos anos, a publicação de artigos científicos tem recebido grande atenção dos sistemas de classificação adotados pelos órgãos de fomento à pesquisa, o que parece estimular ainda mais os pesquisadores a submeterem seus trabalhos a periódicos de maior conceituação em sistemas como o Qualis (Capes) e outros.

No entanto, o desconhecimento das convenções que guiam a organização formal e retórica de alguns gêneros acadêmicos, em especial as do artigo científico, pode tornar o trabalho do pesquisador mais difícil, acarretando, muitas vezes, a rejeição de seu trabalho pela revista. Diante dessa preocupação, alguns autores brasileiros já se dedicaram a escrever sobre a redação acadêmica e suas especificidades (CÁCERES; GÂNDARA; PUGLISI, 2011;NAHAS; FERREIRA, 2005a, b; BARROS NETO, 2011; MOTTA-ROTH; HENDGES, 2010, entre outros).

Tem sido reconhecido que a introdução é responsável por envolver e convencer a comunidade científica sobre a importância e a relevância do estudo. Em 1990, John Swales, preocupado em oferecer um modelo retórico para que seus estudantes de inglês para fins específicos pudessem redigir melhor seus trabalhos, apresentou a forma final de um modelo que vinha desenvolvendo desde 1984, o Modelo Create a Research Space (CARS) - Criar um Espaço de Horizontes de Linguística Aplicada, ano 12, n. 1, 2013164 
Pesquisa. Muito reconhecido entre pesquisadores de gêneros textuais, o modelo, conforme Bezerra (2001, p. 25), "resultou da análise, por parte do autor, de 48 introduções de artigos de pesquisa, divididas em três grupos iguais, provenientes de três áreas científicas diferentes (ciências exatas, biologia/medicina e ciências sociais, incluindo pedagogia, administração e linguística)" e tem sido utilizado até os dias atuais, apesar de ter sido objeto de críticas e revisão inclusive pelo próprio Swales (ver nota 1).

Mesmo assim, a produtividade do modelo mostra-se inclusive nas adaptações recebidas em sua estrutura quando de sua aplicação a gêneros como a resenha acadêmica (MOTTA-ROTH, 1995; ARAÚJO, 1996; BEZERRA, 2001), o abstract de dissertações (BIASIRODRIGUES, 1998) ou os gêneros introdutórios de livros acadêmicos (BEZERRA, 2006). Portanto, trata-se de um modelo de análise testado e aplicado em diversas áreas disciplinares e em diferentes contextos culturais, com adaptações que ressaltam seu caráter flexível e dinâmico, justificando assim sua utilização em diversas pesquisas pelo mundo afora. ${ }^{1}$

No Brasil, entretanto, ainda existe uma carência de estudos dedicados a verificar como as seções dos artigos científicos publicados na literatura nacional estão organizadas retoricamente. $\mathrm{O}$ objetivo deste trabalho é, especificamente, contribuir para a compreensão preliminar de como se organizam as introduções de artigos científicos na área da saúde pública, buscando colaborar com pesquisadores da área de gêneros textuais bem como com aqueles interessados em aprimorar a redação acadêmica. Para tanto, analisamos dez introduções de artigos científicos publicados em periódicos acadêmicos situados na base de dados Scielo no ano de 2012, utilizando, como ferramenta teóricometodológica, o Modelo CARS proposto por Swales (1990).

Para alcançar seus fins, o trabalho está organizado da seguinte forma: no primeiro tópico, tratamos especificamente das introduções

${ }^{1}$ Swales (2004), considerando resultados da aplicação do Modelo CARS por pesquisadores em diferentes áreas do conhecimento, revisa e flexibiliza o modelo em alguns aspectos. No entanto, isso não implica uma desvalorização do Modelo CARS em sua forma "clássica", conforme se pode constatar em Swales (2009). 
de artigos científicos, embasando teoricamente a questão antes de apresentar, no segundo tópico, o Modelo CARS conforme proposto por Swales (1990). Em seguida, apresentamos os procedimentos metodológicos que orientaram a pesquisa, antes de passar, no último tópico, aos resultados e às discussões.

\section{Discutindo a introdução do artigo científico}

Uma das principais metas de um pesquisador, ao se propor a realizar um estudo, é publicar seus resultados, o que, na maioria das vezes, ocorre por meio de um artigo científico. Além da publicação do trabalho, o autor também almeja ganhar a aceitação da comunidade científica na qual está inserido (HYLAND, 2000). Assim, o desafio é ainda maior, pois não basta publicar, é necessário que o texto seja lido e aceito pelos membros da comunidade discursiva. Ademais, é relevante que o artigo aceito e publicado seja também citado por outros pesquisadores. No entanto, alcançar essa aceitação depende, além de fatores como o bom uso da linguagem argumentativa, da familiaridade do autor com as convenções impostas para o gênero pela respectiva comunidade científica (HYLAND, 1996).

Ao escrever, o autor deve selecionar elementos linguísticos e textuais-discursivos que respeitem as convenções ou regras existentes em uma comunidade discursiva particular (HYLAND, 2000). Tais convenções podem assegurar tanto o reconhecimento do trabalho pelos leitores quanto a aceitação pela comunidade científica, como assinalam Bernadino (2007) e Vázquez e Giner (2008).

Em artigos científicos, a seção de introdução funciona como uma porta de entrada para o trabalho no meio acadêmico, possibilitando sua aceitação pelos leitores. Assim, além do resumo/abstract, a introdução, que é também responsável, conforme Nahas e Ferreira (2005a), pela primeira impressão causada pelo artigo ao revisor do periódico, merece especial atenção do autor para que aumentem as chances de publicação do artigo. Aliás, essa percepção da importância da introdução para o sucesso do artigo já orientava o trabalho de Swales (1990). 
Considerando uma perspectiva teórica diferente, Volpato e Freitas (2003) ainda ressaltam que a introdução deve ser escrita após a redação das conclusões, dos resultados, dos materiais e dos métodos e discussão, nesta ordem. Para os pesquisadores, o autor deve ser "sintético e incisivo ao mostrar o problema investigado e as justificativas que suportam o objetivo proposto". Além disso, "definições de termos e importância do estudo podem ser incluídos, se estritamente necessários" (p. 51). Com as devidas diferenças teóricas e terminológicas, podemos afirmar que essa também é basicamente a postura de Swales (1990) com relação à introdução dos artigos de pesquisa. $^{2}$

Diferentes autores, em diferentes áreas do conhecimento, apresentam concepções sobre a introdução dos artigos de pesquisa que reforçam a relevância de se testar e aplicar um modelo de análise tal como o Modelo CARS. Henz (2003, p. 148), por exemplo, acredita que a introdução de um artigo de pesquisa "serve para apresentar o problema estudado, recuperar as informações já publicadas sobre o tema e definir o objetivo do trabalho".

Numa perspectiva um pouco mais prescritiva, Nahas e Ferreira (2005a, p. 13) ressaltam que a introdução tem como objetivo

[...] situar o leitor acerca do que se passa na literatura mundial sobre o assunto. Deve ser concisa e objetiva, principalmente no caso de artigos para revistas. Neste item deve-se demonstrar a relevância do estudo, com citações $e$ estatísticas, de forma bem resumida.

Para Cáceres, Gândara e Puglisi (2011, p. 402), a introdução tem como objetivo principal

2 No entanto, ressalte-se que, conforme lembra Hyland (2008), diferentes comunidades disciplinares expressam suas ideias de formas diferentes e possuem formas diferentes de persuadir seus leitores. As convenções tratadas por Volpato e Freitas (2003) são mais utilizadas nas ciências duras ou hard sciences, como as ciências da saúde, no nosso caso. Dessa forma, não devem ser generalizadas para as soft sciences, como as ciências humanas, por exemplo. 
apresentar resumidamente ao leitor o contexto onde surgiu a questão de pesquisa. $O$ autor deve ser capaz de explorar de forma concisa apenas os tópicos envolvidos no delineamento da pesquisa a partir do seu ponto de vista, relatando a literatura apropriada [...] é importante que o autor relate de forma clara quais lacunas seu trabalho pretende preencher, e a forma mais fácil de fazer isso é apresentar os objetivos de forma pontual e questões (ou hipóteses) que não sejam gerais.

Ainda no mesmo tom prescritivo, Silva et al. (2009, p. 1344) afirmam que a introdução

deve apresentar uma revisão de literatura pertinente, atualizada (preferivelmente publicada nos últimos cinco anos) e específica sobre o tópico abordado, como também indicar o objetivo do tema, destacando a relevância $e$ natureza do problema e das preocupações do autor, bem como os objetivos e principais argumentos que justifiquem o artigo.

Quanto à estrutura da introdução, algumas considerações também já foram feitas. Cáceres, Gândara e Puglisi (2011, p. 402) relatam que

[...] a estrutura da introdução geralmente inicia do que é conhecido ou estabelecido sobre o tema, em direção ao assunto que permanece desconhecido e que será estudado. Essa ponte deve ser explícita para destacar o aspecto inovador da pesquisa.

Para Nahas e Ferreira (2005a, p. 13), o objetivo do trabalho deve ser redigido no último parágrafo. Os autores alegam que "o objetivo é a pergunta à qual o estudo se propõe a responder e, ao final, deverá fazê-lo, seja positiva ou negativamente". Quanto à extensão, uma introdução pode variar de acordo com diferentes áreas. Introduções mais longas seriam típicas das ciências sociais, enquanto a 
brevidade seria uma característica mais comum das ciências naturais e da engenharia.

Com base nessas considerações, observamos que a introdução é, sem dúvida, além de uma seção destinada a introduzir o trabalho que será apresentado, um espaço reservado à busca de interação, convencimento e, principalmente, aceitação pelos leitores. Ao lado disso, acreditamos que o Modelo CARS (SWALES, 1990), tomado em sua "clássica", por sinal a mais testada por diversos pesquisadores, continua sendo uma ferramenta produtiva capaz de possibilitar observações sistemáticas sobre as introduções de artigos de pesquisa, contribuindo para confirmar, corrigir ou refutar as impressões de caráter mais prescritivo defendidas pelos autores da área em estudo.

\section{Apresentando o Modelo CARS (SWALES, 1990)}

Apesar de abertos a manifestações do estilo ou da criatividade individual, os gêneros textuais mantêm em sua composição características exigidas pelas comunidades de usuários e pela natureza das atividades nela desenvolvidas, apresentando, assim, certa estabilidade. Não seria diferente quando se trata de artigos científicos, que, apesar de apresentarem variações dependendo da área de estudo, possuem certa regularidade estrutural e retórica. Levando isso em consideração, desde seu surgimento o Modelo CARS teve como objetivo analisar a estrutura retórica de introduções de artigos de pesquisa em diferentes áreas disciplinares, constituindo, além de um trabalho investigativo, também um trabalho de caráter pedagógico.

O modelo foi composto por três partes argumentativas denominadas "movimentos" (moves), ${ }^{3}$ descritos segundo uma metáfora ecológica, a saber: Movimento 1 - estabelecendo o território da pesquisa; Movimento 2 - estabelecendo o nicho da pesquisa; e Movimento 3 - ocupando o nicho. O Movimento 1 é utilizado pelo autor do texto para apresentar o território em que a pesquisa está

${ }^{3}$ No Brasil, os moves foram rebatizados como "unidades retóricas" por BiasiRodrigues (1998) e Bezerra (2001, 2006).

169 Horizontes de Linguística Aplicada, ano 12, n. 1, 2013 
inserida, território esse bastante extenso. A seguir, no Movimento 2, o esforço retórico tende a diminuir, e o nicho a ser pesquisado é delimitado dentro de seu território previamente definido. Por fim, por meio do Movimento 3, o nicho, entendido como espaço de pesquisa, é ocupado. Cada movimento é realizado por passos (steps), ${ }^{4}$ unidades menores responsáveis pela construção da informação apresentada no texto, que serão apresentados na Tabela $1 .^{5}$

Tabela 1: Modelo CARS SWALES (1990, p. 141)

\begin{tabular}{|c|c|}
\hline Movimentos & Passos \\
\hline $\begin{array}{l}\text { Movimento 1 } \\
\text { Estabelecendo um território }\end{array}$ & $\begin{array}{l}\text { Passo } 1 \text { - Alegando centralidade e/ou } \\
\text { Passo } 2 \text { - Fazendo generalizações sobre o } \\
\text { tópico e/ou } \\
\text { Passo } 3 \text { - Revisando itens de pesquisas } \\
\text { anteriores }\end{array}$ \\
\hline $\begin{array}{c}\text { Movimento } 2 \\
\text { Estabelecendo um nicho }\end{array}$ & $\begin{array}{l}\text { Passo 1A - Contra-argumentando ou } \\
\text { Passo 1B - Indicando uma lacuna ou } \\
\text { Passo 1C - Levantando questionamentos ou } \\
\text { Passo 1D - Continuando uma tradição }\end{array}$ \\
\hline $\begin{array}{c}\text { Movimento } 3 \\
\text { Ocupando o nicho }\end{array}$ & $\begin{array}{l}\text { Passo 1A - Delineando os objetivos ou } \\
\text { Passo 1B - Anunciando a pesquisa } \\
\text { Passo } 2 \text { - Anunciando os principais achados } \\
\text { Passo } 3 \text { - Indicando a estrutura do artigo }\end{array}$ \\
\hline
\end{tabular}

É importante lembrar que os movimentos (moves) são unidades funcionais e não formais, ou seja, não se confundem com sentenças ou com parágrafos, por exemplo. Conforme ressalta Swales (2004, p. 228), o move "é uma unidade discursiva ou retórica que realiza uma função comunicativa coerente no discurso escrito ou oral".

${ }^{4}$ Rotulados por outros pesquisadores como "subfunções" (MOTTA-ROTH, 1995), "estratégias" (ARAÚJO, 1996) ou ainda "subunidades [retóricas]" (BIASI-RODRIGUES, 1998; BEZERRA, 2001).

${ }^{5}$ Em Swales (2004) e em diversos trabalhos que aplicam o modelo proposto pelo autor, o nível dos steps deixou de ser enfatizado em passou-se a destacar apenas os moves. Neste estudo, entretanto, preferimos aplicar o Modelo CARS conforme proposto em 1990, a fim de testar seu funcionamento, inclusive no nível das estratégias retóricas mais específicas, isto é, os steps.

Horizontes de Linguística Aplicada, ano 12, n. 1, 2013170 
Conjuntamente, os movimentos e os passos consistem em estratégias utilizadas pelo autor para atingir um dado objetivo em uma determinada passagem do texto (MOTTA-ROTH, 1995).

De acordo com Swales (1990), os movimentos retóricos refletem o propósito ou os propósitos comunicativos que os membros de uma comunidade pretendem compartilhar, propósitos esses que constituem o fundamento do gênero e são reconhecidos pelos membros especializados da comunidade discursiva. Esse fundamento é responsável por modelar a estrutura esquemática do discurso, influenciando e limitando a escolha de conteúdo e estilo.

Diante disso, o estudo dos movimentos e dos passos que compõem um gênero possibilita o entendimento e a análise de seu funcionamento, além da verificação de como sua organização é feita pelo usuário, podendo sofrer variações dependendo do contexto e da cultura em que está inserido. Apesar de a aplicação do Modelo CARS ter sido bem-sucedida para a análise dos movimentos e dos passos em introduções de artigos científicos, é importante destacar que em contextos acadêmicos e culturais diferentes os gêneros podem sofrer alterações, ocasionando uma mudança no modelo proposto, como mostraram alguns pesquisadores internacionais de diferentes áreas de estudo discutidos por Swales (2009). Na verdade, mesmo no tocante aos artigos científicos, verifica-se que se organizam de forma diferente nas diversas tradições disciplinares, o que impõe adaptações no modelo de análise, aspecto do qual Swales (2004) procura dar conta ao revisitar o tema.

\section{Procedimentos metodológicos}

O corpus deste estudo foi composto por dez artigos científicos publicados em língua portuguesa em revistas nacionais brasileiras e selecionados pelo critério de indexação dos referidos periódicos na base de dados Scielo. Como critérios adicionais para a seleção dos artigos, estes deveriam ter sido publicados no ano de 2012 e abordar o tema "saúde pública". Para maior diversificação da amostra, optamos ainda por escolher cada artigo de uma revista diferente. Assim, de um 
total de 29 artigos inicialmente coletados, apenas dez atenderam aos critérios de inclusão estabelecidos anteriormente.

No Quadro 1, detalhamos o corpus do estudo com informações sobre o título do artigo e o periódico em que foi publicado.

Quadro 1: Constituição do corpus para análise

\begin{tabular}{|c|c|c|}
\hline Artigo & Revista & Título \\
\hline 1 & $\begin{array}{l}\text { Revista de Saúde } \\
\text { Pública }\end{array}$ & $\begin{array}{l}\text { Atividade física durante a gestação e } \\
\text { associação com indicadores de saúde } \\
\text { materno-infantil }\end{array}$ \\
\hline 2 & $\begin{array}{l}\text { Revista Saúde e } \\
\text { Sociedade }\end{array}$ & $\begin{array}{l}\text { O cotidiano na investigação em saúde } \\
\text { pública: um recorte teórico e metodológico }\end{array}$ \\
\hline 3 & $\begin{array}{l}\text { Revista de } \\
\text { Nutrição }\end{array}$ & $\begin{array}{l}\text { Validação de metodologias ativas de } \\
\text { ensino-aprendizagem na promoção da } \\
\text { saúde alimentar infantil }\end{array}$ \\
\hline 4 & $\begin{array}{l}\text { Revista da } \\
\text { Associação Médica } \\
\text { Brasileira }\end{array}$ & $\begin{array}{l}\text { Trabalho noturno e risco cardiovascular } \\
\text { em funcionários de universidade pública }\end{array}$ \\
\hline 5 & Revista Cefac & $\begin{array}{l}\text { Análise das atribuições dos } \\
\text { fonoaudiólogos do Nasf em municípios da } \\
\text { Região Metropolitana do Recife }\end{array}$ \\
\hline 6 & $\begin{array}{l}\text { Revista Brasileira } \\
\text { de Epidemiologia }\end{array}$ & $\begin{array}{l}\text { Síndrome de Burnout em graduandos de } \\
\text { Odontologia }\end{array}$ \\
\hline 7 & $\begin{array}{l}\text { Physis - Revista de } \\
\text { Saúde Coletiva }\end{array}$ & $\begin{array}{l}\text { Integrando a terminologia para entender a } \\
\text { biossegurança }\end{array}$ \\
\hline 8 & $\begin{array}{l}\text { Revista Interface - } \\
\text { Comunicação, } \\
\text { Saúde, Educação } \\
\end{array}$ & $\begin{array}{l}\text { Direito à saúde e integralidade: uma } \\
\text { discussão sobre os desafios e caminhos } \\
\text { para sua efetivação }\end{array}$ \\
\hline 9 & $\begin{array}{l}\text { Acta Paulista de } \\
\text { Enfermagem }\end{array}$ & $\begin{array}{l}\text { Depressão em idosos inscritos no } \\
\text { Programa de Controle de Hipertensão } \\
\text { Arterial e Diabetes Mellitus }\end{array}$ \\
\hline 10 & $\begin{array}{l}\text { Pesquisa } \\
\text { Veterinária } \\
\text { Brasileira }\end{array}$ & $\begin{array}{l}\text { Microbiologia de swabs retais e otológicos } \\
\text { em carnívoros silvestres do zoológico do } \\
\text { Parque Estadual de Dois Irmãos, } \\
\text { Pernambuco }\end{array}$ \\
\hline
\end{tabular}

Uma vez selecionados os artigos a serem estudados, cada uma das respectivas introduções foi analisada à luz do Modelo CARS (SWALES, 1990), buscando-se verificar a ocorrência bem como a 
frequência dos movimentos e dos passos propostos pelo autor. Os resultados dessa análise são descritos e discutidos a seguir.

\section{Organização retórica das introduções dos artigos analisados}

Como posto anteriormente, nossa análise teve como objetivo verificar, nas introduções de artigos de pesquisa em saúde pública, a ocorrência e a frequência dos movimentos retóricos e dos passos propostos pelo Modelo CARS. Como é possível observar na Tabela 2, o Movimentos 1 (Estabelecendo um território) e o Movimento 3 (Ocupando o nicho) estavam presentes em todos os dez artigos. O Movimento 2 (Estabelecendo um nicho) não foi encontrado em um dos artigos analisados.

Tabela 2: Movimentos retóricos presentes nos 10 artigos analisados

\begin{tabular}{cccc}
\hline Artigo & Movimento 1 & Movimento 2 & Movimento 3 \\
1 & $\mathrm{X}$ & $\mathrm{X}$ & $\mathrm{X}$ \\
2 & $\mathrm{X}$ & $\mathrm{X}$ & $\mathrm{X}$ \\
3 & $\mathrm{X}$ & $\mathrm{X}$ & $\mathrm{X}$ \\
4 & $\mathrm{X}$ & $\mathrm{X}$ & $\mathrm{X}$ \\
5 & $\mathrm{X}$ & $\mathrm{X}$ & $\mathrm{X}$ \\
6 & $\mathrm{X}$ & $\mathrm{X}$ & $\mathrm{X}$ \\
7 & $\mathrm{X}$ & $\mathrm{X}$ & $\mathrm{X}$ \\
8 & $\mathrm{X}$ & $\mathrm{X}$ & $\mathrm{X}$ \\
9 & $\mathrm{X}$ & - & $\mathrm{X}$ \\
10 & $\mathrm{X}$ & & $\mathrm{X}$ \\
\hline
\end{tabular}

Ao analisarmos o total de ocorrências dos movimentos, considerando os passos mais frequentemente utilizados pelos autores (Tabela 1), verificamos que o Movimento 1 foi o mais recorrente nos artigos analisados, com uma preferência dos autores primeiramente pelo Passo 1 (Alegando centralidade) e, numa escala ligeiramente decrescente, também pelo Passo 2 (Fazendo generalizações sobre o tópico) e Passo 3 (Revisando itens de pesquisas anteriores), respectivamente.

173 Horizontes de Linguística Aplicada, ano 12, n. 1, 2013 
O Movimento 2 foi o menos empregado, não sendo encontrado nas análises o Passo 1D (Continuando uma tradição). Nesse move, a estratégia mais recorrente foi a utilização do Passo 1A (Contraargumentando) ou do Passo 1B (Indicando uma lacuna).

Quanto ao Movimento 3, a estratégia retórica predominante foi o uso do Passo 1A (Delineando os objetivos), ao lado de apenas uma ocorrência dos Passos 1B (Anunciando a pesquisa) e 2 (Anunciando os principais achados). Não houve ocorrência do Passo 3 (Indicando a estrutura do artigo).

Tabela 3. Ocorrência dos movimentos e dos passos retóricos

\begin{tabular}{|c|c|c|}
\hline Movimentos & Passos & $\begin{array}{c}\text { Total de } \\
\text { ocorrências }\end{array}$ \\
\hline \multirow{3}{*}{ 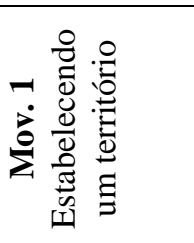 } & Passo 1 - Alegando centralidade & 9 \\
\hline & $\begin{array}{l}\text { Passo } 2 \text { - Fazendo generalizações sobre o } \\
\text { tópico }\end{array}$ & 7 \\
\hline & $\begin{array}{l}\text { Passo } 3 \text { - Revisando itens de pesquisas } \\
\text { anteriores }\end{array}$ & 6 \\
\hline \multirow{4}{*}{ 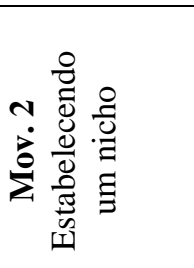 } & Passo 1A - Contra-argumentando & 5 \\
\hline & Passo 1B - Indicando uma lacuna & 4 \\
\hline & Passo 1C - Levantando questionamentos & 2 \\
\hline & Passo 1D - Continuando uma tradição & - \\
\hline \multirow{4}{*}{ 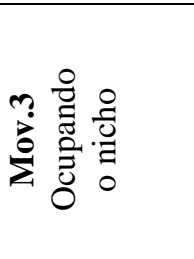 } & Passo 1A - Delineando os objetivos & 10 \\
\hline & Passo 1B - Anunciando a pesquisa & 1 \\
\hline & Passo 2 - Anunciando os principais achados & 1 \\
\hline & Passo 3 - Indicando a estrutura do artigo & - \\
\hline
\end{tabular}

A forte recorrência do Passo 1 do Movimento 1 (Alegando centralidade) explica-se pela importância estratégica de se procurar argumentar e convencer o leitor sobre a relevância do trabalho. Para Swales (1990, p. 144), esse passo é um "apelo à comunidade discursiva através do qual os membros são convidados a aceitarem que

Horizontes de Linguística Aplicada, ano 12, n. 1, 2013174 
a pesquisa a ser relatada é parte de uma área de pesquisa fértil, significativa ou bem estabelecida". Para a construção desse passo, em termos dos elementos linguísticos, podem ser utilizados recursos léxico-gramaticais como adjetivos, conforme se pode observar em destaque no Excerto 1.

\section{Excerto 1: artigo 10}

$O$ estudo epidemiológico de patógenos em populações selvagens no ambiente in situ e ex situ é fundamental para implementação de programas de prevenção, controle $e$ monitoramento de enfermidades e para elaboração de políticas públicas de saúde pública e animal.

O Passo 2 do Movimento 1 (Fazendo generalizações sobre o tópico) é necessário para situar o leitor no assunto que será desenvolvido na pesquisa. Com essa estratégia, os autores apresentam conceitos, estatísticas e informações úteis para o engajamento do receptor do texto. Em nossa análise, verificamos que sete artigos iniciam a introdução utilizando esse passo, como ilustrado no Excerto 2.

\section{Excerto 2: artigo 3}

Conceitualmente, práticas alimentares referem-se à seleção dos alimentos e seu consumo, bem como ao modo de preparo das refeições e à consequente ingestão.

Quanto ao Passo 3 do Movimento 1 (Revisando itens de pesquisas anteriores), a maioria dos artigos apresentou uma revisão de literatura concisa e objetiva, como sugerem Nahas e Ferreira (2005a), atualizada e específica sobre o tema abordado, como alertam Silva et al. (2009) e Henz (2003). O Excerto 3 representa uma das ocorrências prototípicas do Movimento 1, Passo 3.

\section{Excerto 3: artigo 6}

Inicialmente, essa síndrome foi descrita em profissionais cujo contato emocional com pessoas é intenso ${ }^{1-4}$; entretanto, mais recentemente, o conceito de Burnout foi expandido para todos os grupos ocupacionais, incluindo estudantes. Nestes últimos, pode-se citar os trabalhos de Schaufeli et

175 Horizontes de Linguística Aplicada, ano 12, n. 1, 2013 
Análise retórica de introduções de artigos

al. ${ }^{5}$, McManus et al. ${ }^{8}$, Willcock et al. ${ }^{9}$, Carlotto et al. ${ }^{10}$, Ried et al. ${ }^{11}$, Garrosa et al. ${ }^{4}$, Barboza et al. ${ }^{12}$, Maroco et al. ${ }^{13}$, Dyrbye et al. ${ }^{14}$ e Zhang et al. ${ }^{15}$.

A contra-argumentação, primeiro passo do Movimento 2, é, segundo Swales (1990), mais frequentemente introduzida com o uso dos marcadores discursivos adversativos (contudo, porém, todavia, infelizmente, mas), também encontrados em nossa análise. Esse segundo movimento retórico da introdução do artigo científico é responsável por ajudar o autor a estabelecer o nicho de sua pesquisa, ao se contrapor a algum aspecto das pesquisas anteriores. Veja-se o Excerto 4 com o respectivo destaque.

\section{Excerto 4: artigo 2}

Porém, a nutrição $e$ as práticas alimentares são aprendizados sociais, não podendo ser abordadas por uma única perspectiva disciplinar, pois o significado do ato de nutrir e de comer ultrapassa o mero ato biológico.

Ao utilizar o Passo 1B (Indicando uma lacuna) do Movimento 2, o autor tem a intenção de ressaltar que o desenvolvimento daquela temática na literatura apresenta limitações e merece ser mais bem estudada. De acordo com Swales (1990), esse passo pode ser sinalizado por verbos (sofrer, estar limitado a), adjetivos e locuções adjetivas (que consome tempo, insuficiente, caro) ou quantificadores negativos e quase-negativos (poucos, nenhum, muito pouco). Nas nossas análises, verificamos, dentre outros, o advérbio "apenas", o numeral "um" e o adjetivo "escassos", como mostram os Excertos 5 e 6.

\section{Excerto 5: artigo 4}

Apenas um estudo abordou sua relação com a hipertensão arterial [...]

Considerando que o tema foi pouco estudado na população brasileira [...]

\section{Excerto 6: artigo 6}

Estudos na área odontológica são escassos [...] 
Com relação a estudos brasileiros que investigaram a Síndrome de Burnout em estudantes de Odontologia, encontrou-se apenas um trabalho conduzido por Carlotto et al.

A ausência do Movimento 2 em um dos artigos (Artigo 10) que obviamente não invalida o modelo de análise - chama a atenção como um procedimento atípico, explicável provavelmente por um lapso dos autores ou mesmo pelo desconhecimento das convenções genéricas do artigo de pesquisa. Para a visualização mais clara e inequívoca das estratégias adotadas pelos autores, reproduzimos na íntegra a introdução em questão, no Quadro 2.

Como é possível observar, a introdução do artigo inicia-se com o Passo 1 do Movimento 1, destacando a relevância do assunto estudado: o estudo proposto é qualificado como "fundamental". No segundo e terceiro parágrafos, os autores definem conceitos fazendo uma revisão da literatura pertinente (Passo 3 do Movimento 1). Por fim, no quarto parágrafo, os autores delineiam os objetivos da sua pesquisa (Passo 1A do Movimento 3). Em nenhum momento os autores se dedicam a estabelecer o espaço proposto para a contribuição do trabalho, ou seja, os pesquisadores não realizam o Movimento 2 (Estabelecendo um nicho) previsto pelo Modelo CARS como uma marca típica das introduções de artigos de pesquisa. Esse movimento seria responsável por convencer o leitor sobre a importância da abordagem específica a ser realizada pelo artigo.

Quanto ao Movimento 3 (Ocupando o nicho), pudemos perceber em nossas análises que os autores utilizaram com mais frequência o Passo 1A (Delineando os objetivos), que se mostrou recorrente em todo o corpus. Quanto a sua localização, é importante ressaltar que esse passo foi utilizado no último parágrafo em oito dos dez artigos, como fechamento da introdução. Apenas um artigo apresentou os objetivos no primeiro parágrafo e outro no segundo. Este último também incluiu um segundo objetivo no penúltimo parágrafo. O delineamento dos objetivos pode ser realizado pelo emprego do termo "objetivo" ou do verbo "objetivar", como mostram os Excertos 7 e 8 . 
Quadro 2: Ausência do Movimento 2 no Artigo 10

\section{INTRODUÇÃO}

$\mathrm{O}$ estudo epidemiológico de patógenos em populações selvagens no ambiente in situ e ex situ é fundamental para implementação de programas de prevenção, controle e monitoramento de enfermidades e para elaboração de políticas públicas de saúde pública e animal (Jorge et al. 2010).

Salmonella spp. são bactérias Gram-negativas, móveis, que podem infectar a maioria das espécies de animais, entre mamíferos, aves e répteis, inclusive os humanos, sendo considerada uma zoonose de grande importância fecal-oral, ocorrendo principalmente pelo conta to direto ou indireto com animais infectados ou pela ingestão de alimentos ou água contaminada (Carvalho 2006).

A otite é uma enfermidade multifatorial resultante do processo inflamatório da cavidade auditiva tendo origem na região externa e podendo prolongar-se até o sistema vestíbulococlear. Esse processo migratório geralmente é acompanhado por complicações mais graves e extensas (Greene 1993). Malassezia pachydermatis é uma levedura de natureza oportunista, tornando-se patogênica quando há uma alteração no ambiente microbiológico da superfície da pele ou no sistema imunológico do hospedeiro levando a um quadro de otite (Mendes et al. 2011). Outras espécies que também podem provocar otite são Malassezia globosa e M. sympodialis (Coutinho et al. 2006).

Objetivou-se com este trabalho realizar um estudo sobre a ocorrência de Salmonella spp., Malassezia sp. e outros patógenos em swabs retais e otológicos de carnívoros silvestres cativos no zoológico do Parque Estadual de Dois Irmãos, Recife, Pernambuco.

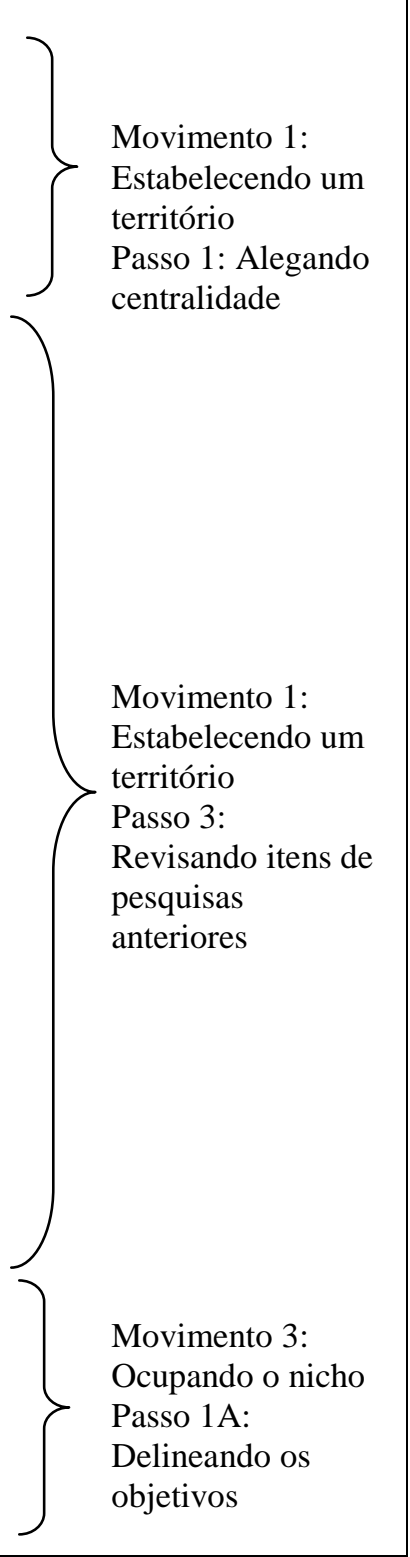




\section{Excerto 7: artigo 5}

Diante disto, este trabalho teve como objetivo, analisar o perfil e as atribuições dos fonoaudiólogos no NASF de acordo com preconizações da portaria $G M N^{o} 154$, de 24 de Janeiro de 2008.

\section{Excerto 8: artigo 3}

Em face do contexto, objetivou-se descrever o processo de validação de metodologias ativas de ensino-aprendizagem na promoção da saúde de crianças do Ensino Fundamental, com vistas ao desenvolvimento de competências para a prática de hábitos alimentares saudáveis.

Os demais passos que poderiam ser utilizados para realizar o move de "ocupar o nicho" foram pouco utilizados, com apenas uma ocorrência para 1B e 2 e nenhuma ocorrência para 3, conforme se pode notar na Tabela 1.

\section{Considerações finais}

Este estudo pretendeu contribuir para a percepção de que os gêneros acadêmicos, dentre eles o artigo científico, refletem os objetivos e as intenções comunicativas dos membros da respectiva comunidade discursiva e têm como finalidade engajar, convencer, persuadir e ganhar aceitação entre os pares. Esses objetivos e intenções apresentam-se de forma privilegiada, no caso do artigo, na seção de introdução. Assim, a análise da organização retórica da introdução, seção responsável pela apresentação do artigo e pela argumentação em torno da relevância do conteúdo do trabalho para o leitor, torna-se importante tanto para pesquisadores da área de gêneros textuais como para os que pretendem iniciar-se ou aprimorar-se na escrita desse gênero. A consciência sobre as convenções prototípicas do gênero certamente ajudará na produção de textos acadêmicos mais coerentes e aceitáveis no quadro sociorretórico de cada disciplina.

Quanto ao modelo de análise, a investigação realizada neste estudo confirma todos os movimentos retóricos propostos por Swales 
(1990), apesar de os artigos em questão terem sido publicados em um contexto acadêmico e cultural diferente daquele exposto pelo autor. $\mathrm{O}$ Modelo CARS continua apresentando um significativo potencial analítico que justifica sua longa sobrevida no campo da análise de gêneros.

Considerando a flexibilidade do modelo, com seus passos alternativos ou opcionais, a ausência de alguns desses passos bem como a menor frequência do Movimento 2 neste estudo podem ser atribuídas pelo menos hipoteticamente às peculiaridades da área disciplinar e talvez ao tamanho reduzido da amostra analisada, totalizando apenas dez artigos científicos. Estudos futuros utilizando corpora maiores, na área disciplinar da saúde pública ou em outra, poderiam confirmar ou não a ocorrência dos passos retóricos não encontrados nesta análise.

\section{Referências}

ARAÚJO, Antonia D. Lexical signalling: a study of unspecific-nouns in book reviews. 1996. Tese (Doutorado em Linguística) - Centro de Comunicação e Expressão, Universidade Federal de Santa Catarina, Florianópolis, 1996.

BARROS NETO, José T. Redação científica: entre a descoberta e a publicação. Revista Brasileira de Botânica, v. 34, n. 1, p. 141-143, 2011.

BERNADINO, Cibele G. $O$ metadiscurso interpessoal em artigos acadêmicos: espaço de negociações e construção de posicionamentos. 2007. Tese (Doutorado em Linguística) - Faculdade de Letras, Universidade Federal de Minas Gerais, Belo Horizonte, 2007.

BEZERRA, Benedito G. A distribuição das informações em resenhas acadêmicas. 2001. Dissertação (Mestrado em Linguística) - Centro de Humanidades, Universidade Federal do Ceará, Fortaleza, 2001. 
—. Gêneros introdutórios em livros acadêmicos. 2006. Tese (Doutorado em Letras) - Centro de Artes e Comunicação, Universidade Federal de Pernambuco, Recife, 2006.

BIASI-RODRIGUES, Bernardete. Estratégias de condução de informações em resumos de dissertações. 1998. Tese (Doutorado em Linguística) - Centro de Comunicação e Expressão, Universidade Federal de Santa Catarina, Florianópolis, 1998.

CÁCERES, Ana M.; GÂNDARA, Juliana P.; PUGLISI, Marina L. Redação científica e a qualidade dos artigos: em busca de maior impacto. Jornal da Sociedade Brasileira de Fonoaudiologia, v. 23, n. 4, p. 401-406, 2011.

DONESCH-JEZO, Ewa. Teaching academic discourse writing in ESP courses for medical students and professionals. US-China Foreign Language, v. 8, n.1, 2010.

HENZ, Gilmar P. Como aprimorar o formato de um artigo científico. Horticultura Brasileira, Brasília, v. 21, n. 2, p. 145-148, 2003.

HYLAND, Ken. Talking to the academy: forms of hedging in science research articles. Written Communication, v.13, n. 2, p. 251-281, 1996.

- Hedges, boosters and lexical invisibility: noticing modifiers in academic texts. Language Awareness, v. 9, n. 4, p. 179-19, 2000.

- Genre and academic writing in the disciplines. Language Teaching, v. 41, n. 4, p. 543-562, 2008.

MOTTA-ROTH, Désirée. Rhetorical features and disciplinary cultures: a genre based study of academic book reviews in linguistics, chemistry and economics. 1995. Tese (Doutorado em Linguística) Centro de Comunicação e Expressão, Universidade Federal de Santa Catarina, Florianópolis, 1995.

MOTTA-ROTH, Désirée; HENDGES, Graciela Rabuske. Produção textual na universidade. São Paulo: Parábola, 2010. 
NAHAS, Fabio X.; FERREIRA, Lydia M. Análise dos itens de um trabalho científico. Acta Cirúrgica Brasileira, v. 20, n. 2, p. 13-16, 2005a.

NAHAS, Fabio X.; FERREIRA, Lydia M. A arte de redigir um trabalho científico. Acta Cirúrgica Brasileira, v. 20, n. 2, p. 17-18, 2005b.

SILVA, Maria J. P. et al. Nursing knowledge production: from the research idea to the publishing in a qualified journal. Revista da Escola de Enfermagem, v. 43, n. 2, p. 1341-1345, 2009.

SWALES, John M. Genre analysis: English in academic and research settings. Cambridge: Cambridge University Press, 1990.

Research genres: explorations and applications. New York: Cambridge University Press, 2004.

- Sobre modelos de análise do discurso. In: BIASIRODRIGUES, Bernardete; ARAÚJO, Júlio César; SOUZA, Socorro C. T. (Org.). Gêneros textuais e comunidades discursivas: um diálogo com John Swales. Belo Horizonte: Autêntica, 2009. p. 33-46.

VÁZQUEZ, Ignacio; GINER, Diana. Beyond mood and modality: epistemic modality markers as hedges in research articles: a crossdisciplinary study. Revista Alicantina de Estudios Ingleses, v. 21, p. 171-190, 2008.

VOLPATO, Gilson L.; FREITAS, Eliane G. Desafios na publicação científica. Pesquisa Odontológica Brasileira, v. 17, n. 1, p. 49-56, 2003.

Submetido em: 11/01/13

Aceito em: 07/04/14

Title: Rhetorical analysis of introductions in public-health-related articles 